\title{
Mobile In-Store Advertising: Exploring the Effects of Location-Based Mobile Promotions on Shopping Behavior: An Abstract
}

\author{
Stefan Brinkhoff and Tobias Schaefers
}

\begin{abstract}
Effective ways to leverage sales in stores using location-based advertising is of increasing interest to both academics and practitioners. Sensors embedded in current mobile phones allow using contextual factors, such as consumers' current outdoor location, for advertising delivery, which was shown to improve customer responses to mobile promotions (Fang et al. 2015; Luo et al. 2014). However, many customers also use their phones inside of stores to gather external information, which influences their purchase decision. Despite a number of studies on mobile advertising, previous literature has not analyzed the effects of in-store push targeting via smartphones on actual shopping behavior. Additionally, only hypothetical evidence exists on how mobile in-store advertising campaigns should be designed to increase effectiveness (e.g., Bues et al. 2017). Therefore, a robust understanding of how mobile advertising influences consumers' shopping behavior inside of a retail location is missing. What is still underexplored is the effectiveness of locationbased mobile promotions during the shopping process. We address this research gap with a unique data set from a 7-month large-scale field experiment, which we conducted in cooperation with a fashion retailer. Specifically, we developed and employed a mobile application that is capable of tracking customers in the store and delivering individualized promotion messages. In a between-subjects experiment, we explore the effects of different promotion types for planned and unplanned shopping categories on 2503 customers' movements and purchasing behavior. The results show that sending mobile promotions during the shopping process increases the average amount of spending and the amount of items per purchase. More importantly, location-based mobile promotions appear to be especially suitable for increasing unplanned purchases and thus creating additional revenue for retailers.
\end{abstract}

\footnotetext{
S. Brinkhoff $\cdot$ T. Schaefers $(\varangle)$

TU Dortmund University, Dortmund, Germany

e-mail: brinkhoff@pfh.de; tobias.schaefers@udo.edu 